\title{
Dopamine Release in Response to a Psychological Stress in Humans and Its Relationship to Early Life Maternal Care: A Positron Emission Tomography Study Using $\left[{ }^{11} \mathrm{C}\right]$ Raclopride
}

\author{
Jens C. Pruessner, ${ }^{1,2}$ Frances Champagne, ${ }^{2}$ Michael J. Meaney, ${ }^{2}$ and Alain Dagher ${ }^{1}$ \\ ${ }^{1}$ McConnell Brain Imaging Center, Montreal Neurological Institute, McGill University, Montreal, Canada H3A 2B4, and 2Douglas Hospital Research Center, \\ Montreal, Canada H4H 1R3
}

\begin{abstract}
Mesolimbic dopamine is thought to play a role in the processing of rewards. However, animal studies also demonstrate dopamine release in response to aversive stressful stimuli. Also, in animal studies, disruptions of the mother-infant relationship have been shown to have long-lasting effects on the mesolimbic dopamine system and the hypothalamic-pituitary adrenal axis. We therefore investigated dopamine release in response to stress in human subjects, considering the relationship to early life parental care. We screened 120 healthy young college students for parental care in early life using a combination of telephone interviews and questionnaires. Five students from the top end and five students from the bottom end of the parental care distribution were then invited for a positron emission tomography study using $\left[{ }^{11} \mathrm{C}\right]$ raclopride and a psychosocial stress task. The psychosocial stressor caused a significant release of dopamine in the ventral striatum as indicated by a reduction in $\left[{ }^{11} \mathrm{C}\right]$ raclopride binding potential in the stress versus resting condition in subjects reporting low parental care. Moreover, the magnitude of the salivary cortisol response to stress was significantly correlated with the reduction in $\left[{ }^{11} \mathrm{C}\right]$ raclopride binding in the ventral striatum $(r=0.78)$, consistent with a facilitating effect of cortisol on dopamine neuron firing. These data suggest that aversive stressful events can be associated with mesolimbic dopamine release in humans, and that the method presented here may be useful to study the effects of early life events on neurobiological stress systems.
\end{abstract}

Key words: stress; dopamine; $\left[{ }^{11} \mathrm{C}\right]$ raclopride; nucleus accumbens; cortisol; maternal care

\section{Introduction}

Numerous animal studies have implicated the dopamine system in the processing of natural and artificial rewards. It has been proposed that mesolimbic dopamine mediates the hedonic aspects of rewarding stimuli (Wise and Rompre, 1989), and that it acts as a learning signal for behavioral reinforcement (Schultz, 1998). These theories account for the reinforcing effects of drugs of abuse and electrical self-stimulation, both of which are known to critically involve the dopamine system. However, the numerous reports of dopamine release in response to aversive stimuli in animals are difficult to fit into theories of reward, which has led to the suggestion that dopamine is more likely involved in motivation and attention underlying the behavioral response to important events, whether aversive or appetitive (Salamone et al., 1997; Berridge and Robinson, 1998; Redgrave et al., 1999).

In animals, microdialysis studies show that dopamine is released in the striatum in response to stressors such as electric shocks and tail pinch (Abercrombie et al., 1989; Rouge-Pont et al., 1993). Stress-induced dopamine release is partly influenced

Received July 21, 2003; revised Jan. 30, 2004; accepted Jan. 31, 2004.

This work was supported by the Canadian Institutes for Health Research, by the Fonds de Recherche en Santé du Québec, and by a research grant from the McGill University Department of Psychiatry to J.C.P.

Correspondence should be addressed to Jens C. Pruessner, Douglas Hospital Research Center, 6875 Boulevard LaSalle, Montreal, Quebec, Canada H4H 1R3. E-mail: jens@bic.mni.mcgill.ca.

DOI:10.1523/JNEUROSCI.3422-03.2004

Copyright $\odot 2004$ Society for Neuroscience $\quad 0270-6474 / 04 / 242825-07 \$ 15.00 / 0$ by circulating cortisol levels (Piazza et al., 1996; Rouge-Pont et al., 1998; Marinelli and Piazza, 2002), which also increase in response to stress. However, it is not known whether aversive events, including psychological stress, cause dopamine release in humans.

Positron emission tomography (PET), with the dopamine $\mathrm{D}_{2}$ receptor radiotracer $\left[{ }^{11} \mathrm{C}\right]$ raclopride, can be used to measure dopamine release in the human brain. There is considerable evidence that manipulations that lead to an increase in synaptic dopamine in the striatum are associated with proportional reductions in binding of this tracer (Breier et al., 1997; Endres et al., 1997; Hartvig et al., 1997; Laruelle et al., 1997; Laruelle, 2000). This technique can be used to measure changes in dopamine levels in response to behavioral tasks in humans (Koepp et al., 1998). In the present study, we investigated dopamine release in humans in response to a psychosocial stress task, to examine whether an adverse stimulus also causes significant changes in $\left[{ }^{11} \mathrm{C}\right]$ raclopride binding.

Finally, a number of animal studies demonstrates that manipulations of early life maternal care have an effect on individual cortisol and dopamine responses to stress across the life span (Liu et al., 1997; Hall et al., 1999). We therefore tried to take this factor into account by choosing our population from a prescreened set of college students with high and low self-reported early life maternal care. We hypothesized that low self-reported early life parental care would be associated with higher cortisol and dopamine levels in response to the psychosocial stress task. 


\section{Materials and Methods}

Subjects and psychological assessment. Subjects were recruited by posting flyers at university buildings and through advertisements in local newspapers for healthy men or women 18-30 years of age. When an individual responded to the advertisement, demographic information and medical history were assessed by telephone. Subjects with a history of head trauma, neurological disorders, drug abuse, or any previous experiences of claustrophobia were excluded from the study. If eligible, the subject was then provided with consent forms and was asked to complete the following psychological questionnaires: the Parental Bonding Index (PBI) (Parker et al., 1979), the Spielberger State-Trait-anxiety inventory (Spielberger et al., 1977), the questionnaire for competence and control for the assessment of self-concept-related self-esteem (Krampen, 1991; Pruessner et al., 1999b), and the Beck Depression Inventory (Beck et al., 1961). One hundred and twenty subjects were screened using these questionnaires. Subjects with a history of depression (assessed during the telephone interview) or who had a score of nine or higher on the Beck inventory were excluded.

Additional analysis emphasized the PBI, which consists of four subscales (mother care, mother overprotection, father care, and father overprotection) comprised of 12 questions each. Because animal studies found dopamine regulation to be affected by differences in maternal care, we used this subscale for subject selection. A cluster analysis was calculated with the maternal care subscale of the questionnaire. The cluster analysis was calculated using the k-means method (Wishart, 1999), forcing a three-group solution, which identified groups with high $(>28 ; n=$ $52)$, low $(<22 ; n=29)$, and intermediate $(n=39)$ scores on the maternal care subscale. On the basis of availability, 10 subjects ( 1 woman and 9 men; 21-30 years of age) were selected as representative of individuals in the top $25 \%$ (scores $>37$ ) and bottom $10 \%$ (scores $<20$ ) of the distribution on the PBI maternal care scale (population mean score, $31.65 \pm 7.6$; range, 12-42) and invited to participate in the PET study. The Montreal Neurological Institute (MNI) Research Ethics Committee approved the study. Written informed consent was obtained from each subject before entering the study.

Behavioral task. Psychological stress was induced using a mental arithmetic task on the basis of a previous psychosocial stress paradigm developed to investigate hormonal stress responses (Pruessner et al., 1999a). Subjects performed mental arithmetic on a computer screen that also displayed information about the total number of errors, expected average number of errors, time spent on the current problem, and performance feedback for each problem (correct, incorrect, timeout). In the modified version used for this experiment, subjects completed a test session before PET scanning and five 6 min arithmetic sessions while being scanned. During the test session, each subject's ability to perform mental arithmetic was assessed by recording the average time to solve problems at different difficulty levels. In the PET session, the time constraint was adjusted to be slightly above each individual's abilities. Subjects were told that the average college student reaches $80-90 \%$ correct answers. Because of the manipulation of the difficulty level, the average performance of the tested subjects was $20-30 \%$ correct answers. In addition, subjects were given negative verbal feedback by the investigator for $\sim 2$ min after each 6 min session, telling them that they needed to improve their performance to reach minimum performance requirements. After the end of the testing session, subjects were debriefed and told that the task was specifically designed to be out of reach of their mental capacity, and that it did not assess their ability to perform mental arithmetic. Although this task is sufficient to elicit a significant hormonal stress response in humans, it must be considered a moderate stressor in comparison with the more widely used public speaking task with regard to cortisol stress responses and self-reported levels of discomfort (Pruessner et al., 1999a). This was implemented in the current study to allow investigation of the stress response in humans in an imaging session. To maintain a constant number of mouse movements across individuals, math problems were presented at a fixed rate by varying the feedback time to compensate for differences in the time allotted to solve the problems, which was varied as a function of each individual's math skills. Subjective perception of stress was assessed using custom-designed visual analog scales (VASs) for feel- ings of helplessness, uncontrollability, threat, embarrassment, and anticipation of negative consequences after the end of the testing session before debriefing.

Cortisol sampling and analysis. Cortisol (nmol/l) was analyzed from saliva samples that were collected every $12 \mathrm{~min}$ throughout the experiment, beginning at the time of PET tracer injection. Cortisol was measured from saliva using a time-resolved fluorescence immunoassay (Dressendorfer et al., 1992). Intra-assay and interassay variability have been shown to be $<10$ and $<12 \%$, respectively. The area under the curve (cortisol in nanomoles per liter by time in minutes) was calculated for each subject and each scanning session using a recently described method (Pruessner et al., 2003). The individual differences between the two groups (high and low parental bonding) and the two conditions (rest and stress session) were then analyzed using a two factor (group by condition) mixed design ANOVA.

Physiological measurements. In addition to cortisol samples, measures of heart rate in beats per minute $(\mathrm{bpm})$, temperature $\left({ }^{\circ} \mathrm{F}\right)$, and skin conductance $(\mu \Omega)$ were performed, starting 10 min before the injection of the tracer and lasting $45 \mathrm{~min}$, to assess physiological responses to the stressor. This was achieved using a computerized system and electrodes placed on the lower left arm, wrist, and chest (F1000 recording system; Focused Technology, Ridgecrest, CA). These data were first grouped in 15 3-min block intervals, and the mean of each block was calculated. These means were subsequently used to calculate the area under the curve values (unit by minutes) for each physiological measure, using a method described recently (Pruessner et al., 2003). These values were then entered into a two-factor mixed-design (group by time) ANOVA.

PET acquisition and analysis. Each subject underwent two $\left[{ }^{11} \mathrm{C}\right]$ raclopride PET scans, one during the behavioral stress task and one while resting. For the stress scanning session, subjects performed the mental arithmetic task continuously from 10 min before until 28 min after the $\left[{ }^{11} \mathrm{C}\right]$ raclopride injection, except for the 2 min feedback blocks between each 6 min math task block. During the rest session, subjects were lying with their eyes closed for the entire scan. No behavioral intervention was performed with the subjects during the testing period in the rest session; however, cortisol and VAS measures were obtained as in the stress session.

The two PET scans were obtained on separate days at the same time of day, with the order of the rest and stress scans counterbalanced across subjects. PET images ( 63 slices, 26 time frames of $60 \mathrm{~min}$ total duration) were obtained with a CTI-Siemens HR +63 slice tomograph (Siemens AG, Erlangen, Germany) operated in three-dimensional acquisition mode, yielding images with an approximate resolution of $4.6 \mathrm{~mm}$ full width at half maximum. For each scan, $8-10 \mathrm{mCi}$ of $\left[{ }^{11} \mathrm{C}\right]$ raclopride was injected into the left antecubital vein for $>1 \mathrm{~min}$. A transmission scan with a rotating rod source was performed for attenuation correction before the injection of radio tracer.

PET frames were summed, coregistered with the individual magnetic resonance imagings (MRIs), and transformed into standardized stereotaxic space (Talairach and Tournoux, 1988) by means of an automated feature-matching algorithm to the MNI template (Collins et al., 1994). Voxelwise $\left[{ }^{11} \mathrm{C}\right]$ raclopride binding potential (BP) was calculated using a simplified reference tissue compartmental model (Lammertsma and Hume, 1996; Gunn et al., 1997) to generate statistical parametric images of change in binding (Aston et al., 2000). We have shown previously that $\left[{ }^{11} \mathrm{C}\right]$ raclopride BP determined with this method is insensitive to changes in regional cerebral blood flow (Aston et al., 2000). The reference tissue used was the cerebellum, which was drawn on five adjacent slices in each subject. BP values were extracted from each PET scan with regions of interest drawn on the subject's MRI over the caudate nucleus, putamen, and ventral striatum. These regions of interest were drawn on the MRI transformed into stereotaxic space, on the basis of the method described by Martinez et al. (2003). In the dorsoventral direction, the regions for the caudate were drawn from $z=4-16 \mathrm{~mm}$, for the putamen from $z=$ $4-10 \mathrm{~mm}$, and for the ventral striatum from $z=-6$ to $-10 \mathrm{~mm}$.

Statistical significance was assessed in two ways. For the statistical map, which was the primary measure, the $t$ threshold was determined using random field theory (Worsley et al., 1996). This method corrects for multiple comparisons on the basis of the search volume and spatial 


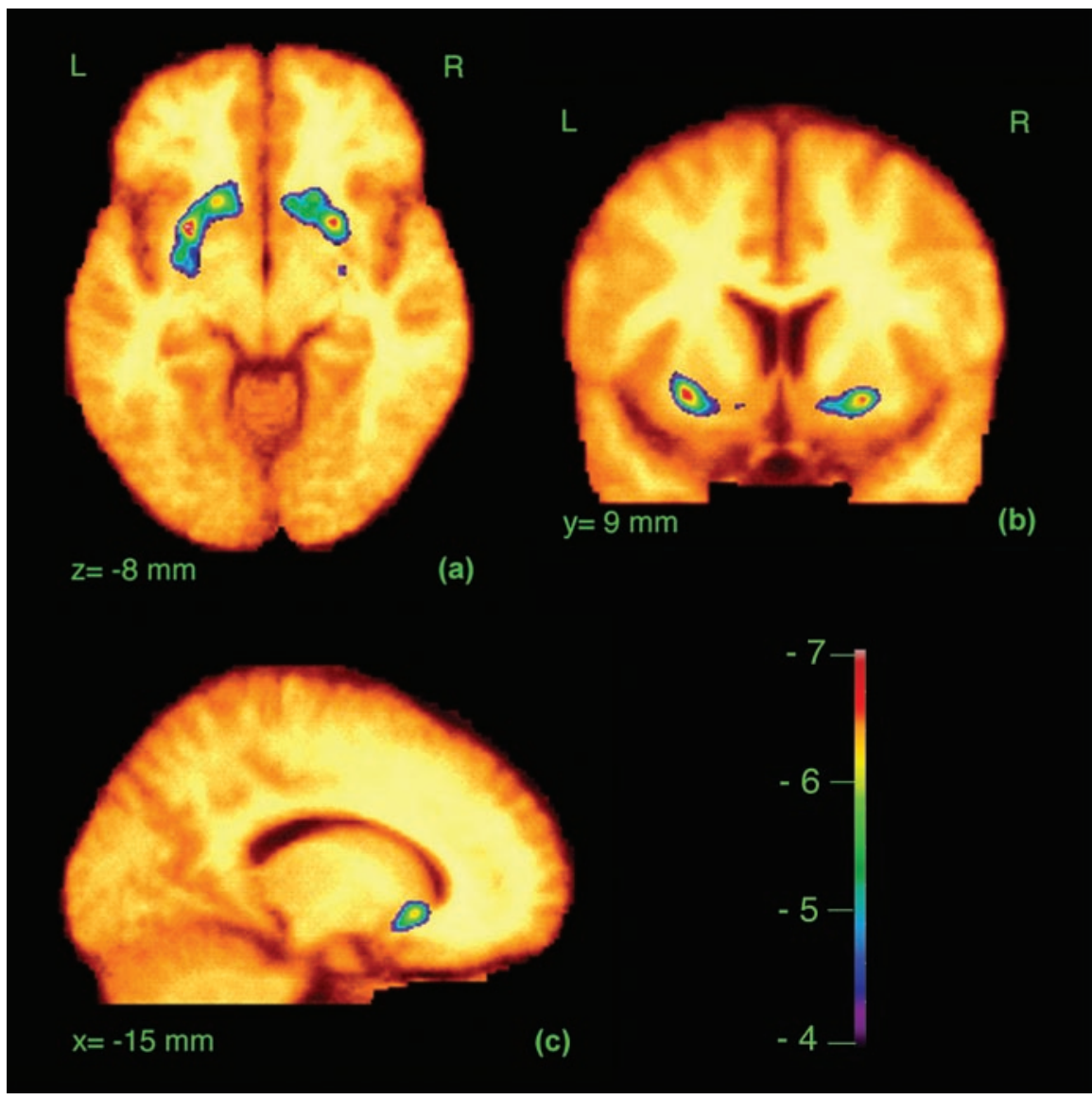

Figure 1. Statistical parametric map showing the t-statistic for a reduction in $\left[{ }^{11} \mathrm{C}\right]$ raclopride $\mathrm{BP}$ in the stress condition compared with the rest condition for all subjects. The t-values in color are overlaid on the average MRI for all subjects transformed into standard stereotaxic space. $a-c, B P$ changes are shown in transverse $(a)$, coronal ( $b$ ), and sagittal ( $c$ ) views. L, Left; $R$, right.

resolution of the image. Because $\left[{ }^{11} \mathrm{C}\right]$ raclopride only binds specifically within the striatum, we defined the search volume in the striatum as all voxels with a mean $B P>1$. This region was $60,688 \mathrm{~mm}^{3}$ in volume. We set the effective image resolution to $10 \mathrm{~mm}$ full width at half maximum. By estimating the degrees of freedom as described previously (Aston et al., 2000), we calculated that a threshold of $t=4.01$ was equivalent to $p=$ 0.05 corrected for multiple comparisons. In addition, the region of interest data were analyzed using a two-factor mixed-design (group by time) ANOVA. Although the regions of interest were drawn bilaterally, we did not include laterality as a factor in the analysis (given the small number of subjects and the subsequent low power to test for additional factors). The $\mathrm{BP}$ values from the regions of interest of the two hemispheres were averaged and entered into the database for statistical analysis.

\section{Results}

\section{Psychological, physiological, and endocrine measurements}

We studied two subpopulations selected on the basis of PBI scores to examine whether parental bonding in early life might be associated with individual differences in neuroendocrine and brain dopamine responses to a stressful condition. We chose five subjects from the top 25\% (maternal care scores $>37$ ) and five subjects from the bottom $10 \%$ (maternal care scores $<10$ ) of PBI scores from a group of previously screened college students as recruits for the PET study. A one-factor (group) ANOVA revealed significant differences in trait anxiety scores between these two groups (high maternal care group, $28.0 \pm 10.42$; low maternal care group, $55.0 \pm 3.16 ; F=30.8 ; \mathrm{df}=8 ; p<0.001)$ and in self-esteem scores (high maternal care group, $36.8 \pm 5.3$; low maternal care group, $23.6 \pm 8.6 ; F=8.5 ; \mathrm{df}=8 ; p=0.02$ ). To test whether group differences were also apparent between state measures, we entered the state anxiety and VAS scores as dependent variables in a two-factor mixeddesign (group by session) ANOVA. Between the groups, no differences emerged in state anxiety $(F=1.3$; NS) or VAS scores $(F=1.64 ; \mathrm{NS})$; similarly, the group by session interaction effect was not significant ( $F=1.49$; NS). However, subjects reported higher state anxiety scores after the stress session when compared with the rest session $(F=3.4 ; p<0.05)$. Likewise, subjects reported higher scores on the VAS after the stress condition, as indicated by the ANOVA (mean difference, $-3.12 \pm$ $1.3 ; F=79.95 ; \mathrm{df}=8 ; p<0.001)$ and confirmed using post hoc comparisons. Comparing the performance between the two groups of subjects is difficult, because the computer program adjusted the level of difficulty individually for each subject on the basis of performance. However, by computing a "number of correct answers per trial to time limit" ratio, we estimated a performance measure. Comparing this measure between the two groups did not result in significant differences $(F<1$; $p>0.20)$.

Compared with the rest session, the stress session resulted in significant increases in salivary cortisol levels, as indicated by a two-factor (group by time) within-design ANOVA analysis (mean difference, $23.53 \pm 15.55 ; F=43.9 ; \mathrm{df}=8$; $p<0.001)$. The same ANOVA also revealed a significant group effect on the cortisol response (low maternal care group, $34.34 \pm 12.2$; high maternal care group, $12.72 \pm 10.14 ; F=11.8 ; \mathrm{df}=8 ; p=0.008)$ and a significant group by session interaction effect $(F=9.29$; $\mathrm{df}=8$; $p<0.02)$. Post hoc comparisons confirmed that the low PBI group showed higher overall cortisol responses and a higher increase of cortisol during the stress session when compared with the control session. Significant differences between the two scanning sessions could also be found for heart rate (mean difference, 56.07 \pm 19.66; $F=$ 132.2; $\mathrm{df}=8 ; p<0.001$ ), skin temperature (mean difference, $-13.16 \pm 16.24 ; F=5.74 ; \mathrm{df}=8 ; p=0.05)$, and skin conductance (mean difference, $20.21 \pm 10.04 ; F=31.8$; df $=8 ; p<$ $0.001)$. Post hoc comparisons revealed that during the stress session, heart rate was higher, skin temperature was lower, and skin conductance was higher when compared with the rest session. However, there was no group $(F<1$; NS) or group by condition interaction effect on heart rate $(F<1$; NS), no group $(F<1$; NS) or group by condition interaction effect on skin temperature $(F<1$; NS), and no group $(F=1.7 ; \mathrm{NS})$ or group by condition effect on skin conductance $(F<1$; NS). All values are area under the curve calculations (unit by minute) of the experimental and rest condition.

\section{PET measurements}

During the stress condition, $\left[{ }^{11} \mathrm{C}\right]$ raclopride $\mathrm{BP}$ in bilateral ventral striatum was significantly reduced compared with the rest condition, as shown by the statistical map (Fig. 1) and confirmed 
by the region of interest analysis $\left(F_{(1,8)}=\right.$ $8.22 ; p=0.02$ ) (Table 1 ), suggesting a taskrelated increase of extracellular levels of dopamine. The location of the peak signal changes and $t$ values are shown in Table 2. We cannot comment on possible dopamine release occurring outside the striatum, because the specific $\left[{ }^{11} \mathrm{C}\right]$ raclopride binding in these areas is too small to measure dopamine receptor availability.

We found a significant effect of the perceived maternal care on stress-induced changes in $\left[{ }^{11} \mathrm{C}\right]$ raclopride $\mathrm{BP}$ in the ventral striatum. Post hoc analysis revealed a significant decrease in $\left[{ }^{11} \mathrm{C}\right]$ raclopride $\mathrm{BP}$ during the stress condition in the low, but not high, maternal care group $\left(F_{(1,8)}=\right.$ 7.78; $p=0.02$ ) (Fig. 2). Finally, we were able to observe a highly significant correlation between the magnitude of the cortisol response to stress and the reduction in $\left[{ }^{11} \mathrm{C}\right]$ raclopride $\mathrm{BP}$ in the ventral striatum across all subjects $(r=0.78 ; p=0.008)$ (Fig. 3).

\section{Discussion}

We have shown that an anxiety-inducing stress task is associated with significant dopamine release in the ventral striatum in healthy human subjects. Although animal studies have demonstrated stress-induced increases in dopamine before, this is, to the best of our knowledge, the first study in humans showing the release of dopamine in response to an aversive stressful task. These findings appear to be at odds with theories of dopamine functioning as a reward signal and more supportive of theories that emphasize motivation, incentive, sensorimotor integration, or attention to action (Bindra, 1978; Salamone et al., 1997; Berridge and Robinson, 1998; Ikemoto and Panksepp, 1999; Redgrave et al., 1999). These theories would predict a role for dopamine in responding to aversive as well as appetitive stimuli.

The reduction in $\left[{ }^{11} \mathrm{C}\right]$ raclopride $\mathrm{BP}$ in the ventral striatum region of interest during stress compared with rest averaged $-10 \%$ ( 5 to $-30 \%$ ), which is greater than the reported $7 \%$ testretest reliability of this method (Wang et al., 1999). The magnitude of the change observed in this experiment is of the same order $(10-15 \%)$ as that observed using the same PET method to detect dopamine release after administration of amphetamine (Leyton et al., 2002) or alcohol (Boileau et al., 2003) or while playing a video game (Koepp et al., 1998).

In the current study, the amount of dopamine released, as indicated by the reduction of $\left[{ }^{11} \mathrm{C}\right]$ raclopride $\mathrm{BP}$, was proportional to the cortisol response to the task. This was shown by the group difference in salivary cortisol response to stress (higher in the low PBI group) and by the correlation between dopamine and cortisol release. The high correlation between the two values ( $r=$ 0.78) suggests a close link between the cortisol and dopamine stress responses. Whether this association is based on a common psychological or pharmacological mechanism is unclear; however, there is evidence from the animal literature supporting a link between the two systems. For example, adrenalectomy reduces both basal levels and stress or drug-induced augmentations of dopamine in the ventral striatum, and this effect can be reversed by corticosterone administration (Piazza et al., 1996; Rouge-Pont et al., 1998; Marinelli and Piazza, 2002). Corticos-
Table 2. Peak change in $\left[{ }^{11} \mathrm{C}\right]$ Raclopride binding potential

\begin{tabular}{llll}
\hline Region & MNI coordinates & Talairach coordinates & Tstatistic \\
\hline Left ventral putamen & $-28,8,-8$ & $-25,4,-7$ & 6.8 \\
Left nucleus accumbens & $-16,18,-6$ & $-15,14,-5$ & 6.3 \\
Right ventral putamen & $24,10,-8$ & $20,6,-7$ & 6.3 \\
Right nucleus accumbens & $18,18,-8$ & $15,14,-7$ & 5.5 \\
\hline
\end{tabular}

Statistical peaks showing the regions where binding potential was greater during the control than during the stres condition. A T value of 4.01 corresponds to a $p$ value of 0.05 corrected. The $x, y$, and $z$ coordinates (in millimeters) refer to the stereotaxic space. The first column lists the true peak coordinates in our experiment, which are in so-called MNI space, because they were obtained as a result of using the MNI template for transforming subject MRIs to stereotaxic space. For comparison with the atlas of Talairach and Tournoux (1988), we computed Talairach coordinates using the following formula: $x^{\prime}=0.88 x-0.8 ; y^{\prime}=0.97 y-3.32 ; z^{\prime}=0.05 y+0.88 z-0.44$. (See http://www.mrc-cbu.cam.ac.uk/Imaging/Common/mnispace.shtml for details.)

terone, acting via glucocorticoid receptors on ventral tegmental area dopamine neurons, increases dopamine neuron firing in response to glutamatergic stimulation (Cho and Little, 1999).

Although $\left[{ }^{11} \mathrm{C}\right]$ raclopride PET has been used to measure changes in extracellular dopamine levels after pharmacological stimulation (Breier et al., 1997; Smith et al., 1997; Volkow et al., 1997; Leyton et al., 2002; Boileau et al., 2003; Martinez et al., 2003), there have been few studies using behavioral tasks. Koepp et al. (1998) detected a reduction in striatal $\left[{ }^{11} \mathrm{C}\right]$ raclopride BP in healthy volunteers playing a video game for a monetary reward. The behavioral task in that study had similarities to the one used here, in that subjects used a computer mouse to play a game displayed on a monitor. However, there was no information on stress levels of the subjects in the video game experiment. More recently, it was shown that a metabolic stressor (acute glucose deprivation after injection of 2-deoxyglucose), which led to selfreported feelings of anxiety, was associated with a significant reduction in striatal $\left[{ }^{11} \mathrm{C}\right]$ raclopride binding (Adler et al., 2000). Glucose deprivation is one of the strongest stimulants for the hypothalamic-pituitary-adrenal (HPA) axis, causing significant amounts of ACTH and cortisol to be released into the bloodstream (Adler et al., 2000). Finally, another PET study also reported reductions in $\left[{ }^{11} \mathrm{C}\right]$ raclopride binding in the ventral striatum in association with a stressful monetary reward task (Pappata et al., 2002). However, the change in binding was only present when the task was associated with a financial reward. The PET methodology of Pappata et al. (2002) was quite different 


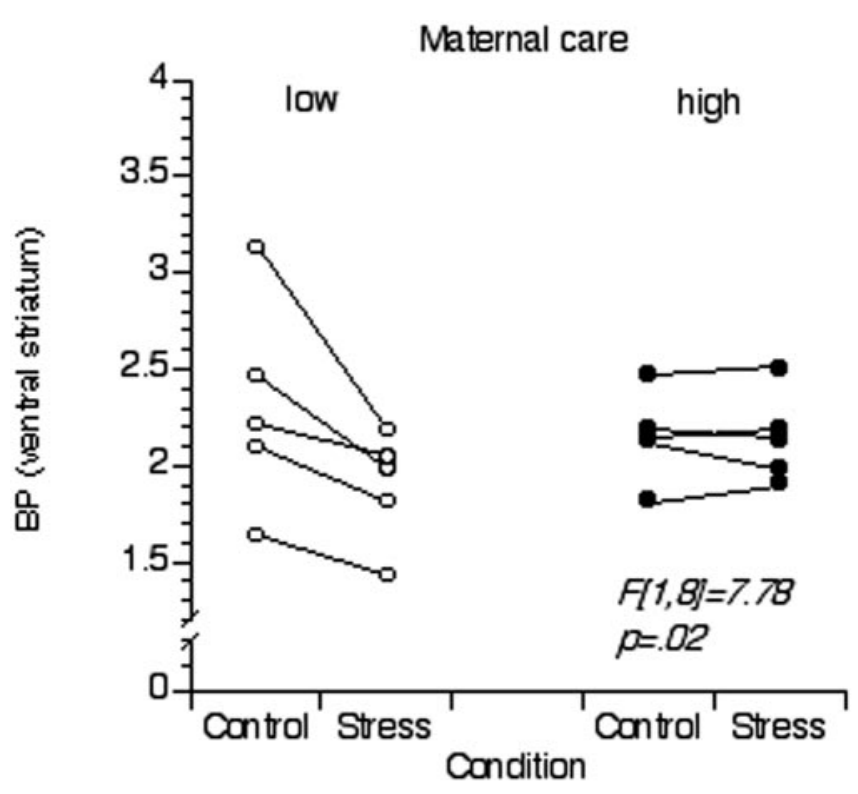

Figure 2. Group differences. Binding potential values extracted from each PET scan with regions of interest drawn on the subject's MRI over the ventral striatum are shown. Values for the two groups of subjects (low and high in maternal care) for the rest and stress scans are displayed. Repeated measures ANOVA showed a significant difference between the two groups.

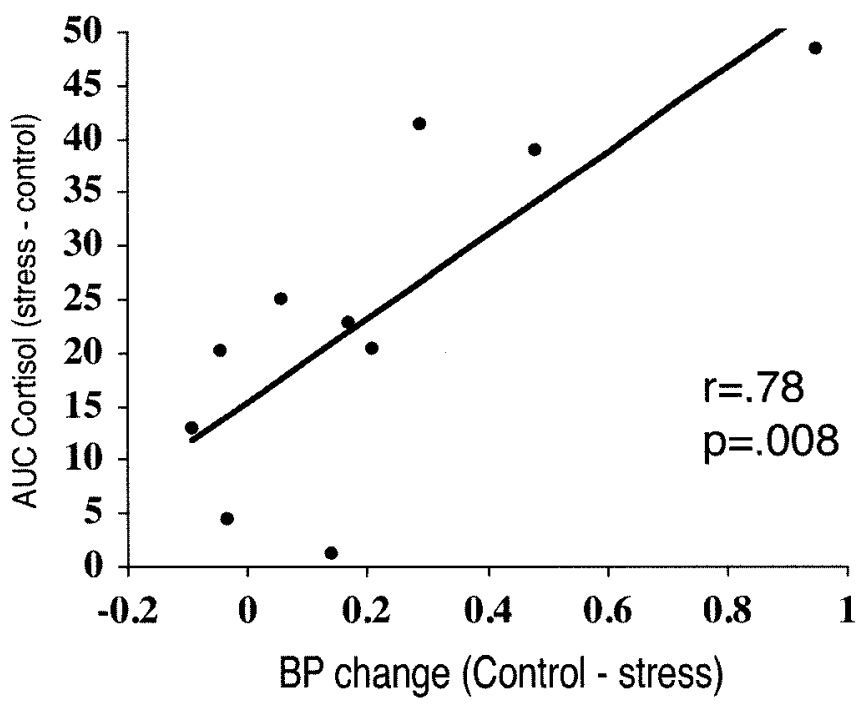

Figure 3. Plot of the correlation between $\left[{ }^{11} \mathrm{C}\right]$ raclopride BP change in the ventral striatum and cortisol stress response differences between the two conditions. The cortisol response is the difference in the total area under the curve of salivary cortisol ( $\mathrm{nmol} / \mathrm{l} \times \mathrm{min}$ ) between stress and resting conditions.

from the one used here, which limits comparison with the current results.

Both the dopaminergic and corticosteroid responses to stress in our experiment were related to self-reported early life maternal care. Although these findings are correlational, the evidence from animal studies indicates that variations in maternal care can directly alter the development of these systems. In rodents, maternal care of pups in early life has significant effects on fear responses in adulthood. Animals that experience lower levels of licking and grooming as pups display increased fearfulness as well as enhanced HPA and adrenergic responses to novelty (Liu et al., 1997; Caldji et al., 1998). These changes are associated with altered expression of gene coding for brain corticotrophin- releasing factor and glucocorticoid receptor. The enhanced HPA response is possibly mediated by reduced feedback sensitivity to circulating corticosterone resulting from lower levels of glucocorticoid receptors in the hippocampus (Liu et al., 1997).

Studies using maternal separation paradigms also suggest that alterations in the mother-infant relationship have an enduring influence on dopamine release in response to drugs or stress (Matthews et al., 1996; Liu et al., 1997; Hall, 1998; Hall et al., 1999; Meaney et al., 2002). For example, adult rats that were separated from their mother in early life have fewer dopamine reuptake transporters, most prominently in the ventral striatum (Meaney et al., 2002). This could lead to a greater and more persistent increase in synaptic dopamine in response to many stimuli, including stress. Together, the results of studies in rodents are consistent with the idea that maternal care can permanently alter the development of neural systems that regulate responses to stress. Few human studies have addressed the relationship between early life experiences and neurobiological response to stress in adulthood. Luecken (1998) found that adults who described poor family relationships had greater cortisol response to a laboratory stress task than control subjects. Similarly, Heim et al. (2000) reported greater increases in plasma ACTH and cortisol levels during a psychosocial stress task in women with a history of childhood abuse than in control subjects.

We cannot exclude the possibility that other personality and neurobiological variables accounted for the observed differences in dopamine release. For example, there were differences in selfesteem between the groups, which could be a consequence of differences in parental bonding. The missing differences between the two groups in perceived level of stress or VAS emotional scores could well be a result of the small statistical power resulting from the small number of subjects. Also, there are many more behavioral variables to look at that might reveal additional group differences. Future studies will have to perform a more thorough behavioral screening to investigate behavioral correlates of parental bonding in larger groups. Finally, although we excluded subjects who gave a history of clinical conditions such as anxiety disorder or alcoholism, we could have missed such a diagnosis because we did not screen for psychiatric illness (other than current depression) using formal detection methods.

Recent theories about dopamine firing being related to prediction errors also need to be taken into account (Schultz, 1998; Suri, 2002). Animal data suggest that dopamine firing increases after an unexpected reward and decreases below baseline after the withholding of an expected reward. This could potentially explain the current results if low parental bonding subjects were expecting to fail, whereas the high parental bonding subjects were expecting to succeed in the math task. Successes would have led to dopamine release in the low parental bonding group only, whereas failures would have reduced dopamine neuron firing only in the high parental bonding group. The difference in the self-esteem measure between the two groups is somewhat supportive of this idea, although we did not measure failure or success expectations directly.

A potential criticism of our paradigm is that the baseline task was a rest condition. It could be argued that hand movement during the stress task could lead to dopamine release independently of stress. However, although it is not known whether hand movements are associated with striatal dopamine release in humans, one would expect that if this occurred, it would affect the motor striatum (i.e., main body of the putamen, contralateral to the hand that is moving). Our finding of dopamine release in the bilateral nucleus accumbens is more in keeping with a stress re- 
sponse, as is the correlation between the change in $\left[{ }^{11} \mathrm{C}\right]$ raclopride binding and cortisol release. Finally, the task design was such that all subjects made the same number of movements during the stress scan, regardless of maternal care group or stress level.

The effect of self-reported early life parental bonding on the dopaminergic and stress response in adulthood described here, although consistent with the animal literature, must be interpreted with caution given the relatively small number of subjects studied and the retrospective nature of the parental bonding questionnaire. This result will ideally need to be replicated with different populations. Likewise, the nonsignificant differences between the two groups of subjects in any of the state measures (state anxiety and VAS) need to be considered with caution because of the small number of subjects and the resulting low statistical power.

Finally, the current findings suggest that this PET technique could be used to identify environmental effects on brain development that may represent risk factors for the later occurrence of disease. For example, it has been proposed that an exaggerated dopamine response to drugs or stress may confer vulnerability to drug addiction (Piazza et al., 1991; Rouge-Pont et al., 1993, 1998; Marinelli and Piazza, 2002).

\section{References}

Abercrombie ED, Keefe KA, DiFrischia DS, Zigmond MJ (1989) Differential effect of stress on in vivo dopamine release in striatum, nucleus accumbens, and medial frontal cortex. J Neurochem 52:1655-1658.

Adler CM, Elman I, Weisenfeld N, Kestler L, Pickar D, Breier A (2000) Effects of acute metabolic stress on striatal dopamine release in healthy volunteers. Neuropsychopharmacology 22:545-550.

Aston JA, Gunn RN, Worsley KJ, Ma Y, Evans AC, Dagher A (2000) A statistical method for the analysis of positron emission tomography neuroreceptor ligand data. NeuroImage 12:245-256.

Beck AT, Ward CH, Mendelson M (1961) An inventory for measuring depression. Arch Gen Psychiatry 4:53-61.

Berridge KC, Robinson TE (1998) What is the role of dopamine in reward: hedonic impact, reward learning, or incentive salience? Brain Res Brain Res Rev 28:309-369.

Bindra D (1978) How adaptive behavior is produced: a perceptualmotivation alternative to response reinforcement. Behav Brain Sci 1:41-91.

Boileau I, Assaad JM, Pihl RO, Benkelfat C, Leyton M, Diksic M, Tremblay RE, Dagher A (2003) Alcohol promotes dopamine release in the human nucleus accumbens. Synapse 49:226-231.

Breier A, Su TP, Saunders R, Carson RE, Kolachana BS, de Bartolomeis A, Weinberger DR, Weisenfeld N, Malhotra AK, Eckelman WC, Pickar D (1997) Schizophrenia is associated with elevated amphetamine-induced synaptic dopamine concentrations: evidence from a novel positron emission tomography method. Proc Natl Acad Sci USA 94:2569-2574.

Caldji C, Tannenbaum B, Sharma S, Francis D, Plotsky PM, Meaney MJ (1998) Maternal care during infancy regulates the development of neural systems mediating the expression of fearfulness in the rat. Proc Natl Acad Sci USA 95:5335-5340.

Cho K, Little HJ (1999) Effects of corticosterone on excitatory amino acid responses in dopamine-sensitive neurons in the ventral tegmental area. Neuroscience 88:837-845.

Collins DL, Neelin P, Peters TM, Evans AC (1994) Automatic 3D intrersubject registration of MR volumetric data in standardized Talairach space. J Comput Assist Tomogr 18:192-205.

Dressendorfer RA, Kirschbaum C, Rohde W, Stahl F, Strasburger CJ (1992) Synthesis of a cortisol-biotin conjugate and evaluation as a tracer in an immunoassay for salivary cortisol measurement. J Steroid Biochem Mol Biol 43:683-692.

Endres CJ, Kolachana BS, Saunders RC, Su T, Weinberger D, Breier A, Eckelman WC, Carson RE (1997) Kinetic modeling of [11C]raclopride: combined PET-microdialysis studies. J Cereb Blood Flow Metab 17:932-942.

Gunn RN, Lammertsma AA, Hume SP, Cunningham VJ (1997) Parametric imaging of ligand-receptor binding in PET using a simplified reference region model. NeuroImage 6:279-287.

Hall FS (1998) Social deprivation of neonatal, adolescent, and adult rats has distinct neurochemical and behavioral consequences. Crit Rev Neurobiol 12:129-162.

Hall FS, Wilkinson LS, Humby T, Robbins TW (1999) Maternal deprivation of neonatal rats produces enduring changes in dopamine function. Synapse 32:37-43.

Hartvig P, Torstenson R, Tedroff J, Watanabe Y, Fasth KJ, Bjurling P, Langstrom B (1997) Amphetamine effects on dopamine release and synthesis rate studied in the Rhesus monkey brain by positron emission tomography. J Neural Transm 104:329-339.

Heim C, Newport DJ, Heit S, Graham YP, Wilcox M, Bonsall R, Miller AH, Nemeroff CB (2000) Pituitary-adrenal and autonomic responses to stress in women after sexual and physical abuse in childhood. JAMA 284:592-597.

Ikemoto S, Panksepp J (1999) The role of nucleus accumbens dopamine in motivated behavior: a unifying interpretation with special reference to reward-seeking. Brain Res Brain Res Rev 31:6-41.

Koepp MJ, Gunn RN, Lawrence AD, Cunningham VJ, Dagher A, Jones T, Brooks DJ, Bench CJ, Grasby PM (1998) Evidence for striatal dopamine release during a video game. Nature 393:266-268.

Krampen G (1991) Fragebogen zu Kompetenz- und Kontrollueberzeugungen (FKK). Göttingen: Hogrefe.

Lammertsma AA, Hume SP (1996) Simplified reference tissue model for PET receptor studies. NeuroImage 4:153-158.

Laruelle M (2000) Imaging synaptic neurotransmission with in vivo binding competition techniques: a critical review. J Cereb Blood Flow Metab 20:423-451.

Laruelle M, Iyer RN, al-Tikriti MS, Zea-Ponce Y, Malison R, Zoghbi SS, Baldwin RM, Kung HF, Charney DS, Hoffer PB, Innis RB, Bradberry CW (1997) Microdialysis and SPECT measurements of amphetamineinduced dopamine release in nonhuman primates. Synapse 25:1-14.

Leyton M, Boileau I, Benkelfat C, Diksic M, Baker G, Dagher A (2002) Amphetamine-induced increases in extracellular dopamine, drug wanting, and novelty seeking a PET/[11C]raclopride study in healthy men. Neuropsychopharmacology 27:1027-1035.

Liu D, Diorio J, Tannenbaum B, Caldji C, Francis D, Freedman A, Sharma S, Pearson D, Plotsky PM, Meaney MJ (1997) Maternal care, hippocampal glucocorticoid receptors, and hypothalamic-pituitary-adrenal responses to stress. Science 277:1659-1662.

Luecken LJ (1998) Childhood attachment and loss experiences affect adult cardiovascular and cortisol function. Psychosom Med 60:765-772.

Marinelli M, Piazza PV (2002) Interaction between glucocorticoid hormones, stress and psychostimulant drugs. Eur J Neurosci 16:387-394.

Martinez D, Slifstein M, Broft A, Mawlawi O, Hwang DR, Huang Y, Cooper T, Kegeles L, Zarahn E, Abi-Dargham A, Haber SN, Laruelle M (2003) Imaging human mesolimbic dopamine transmission with positron emission tomography. Part II: amphetamine-induced dopamine release in the functional subdivisions of the striatum. J Cereb Blood Flow Metab 23:285-300.

Matthews K, Hall FS, Wilkinson LS, Robbins TW (1996) Retarded acquisition and reduced expression of conditioned locomotor activity in adult rats following repeated early maternal separation: effects of prefeeding, d-amphetamine, dopamine antagonists and clonidine. Psychopharmacology (Berl) 126:75-84.

Meaney MJ, Brake W, Gratton A (2002) Environmental regulation of the development of mesolimbic dopamine systems: a neurobiological mechanism for vulnerability to drug abuse? Psychoneuroendocrinology 27:127-138.

Pappata S, Dehaene S, Poline JB, Gregoire MC, Jobert A, Delforge J, Frouin V, Bottlaender M, Dolle F, Di Giamberardino L, Syrota A (2002) In vivo detection of striatal dopamine release during reward: a PET study with $[(11) \mathrm{C}]$ raclopride and a single dynamic scan approach. NeuroImage 16:1015-1027.

Parker G, Tupling H, Brown LB (1979) A parental bonding instrument. Br J Med Psychology 52:1-10.

Piazza PV, Rouge-Pont F, Deminiere JM, Kharoubi M, Le Moal M, Simon H (1991) Dopaminergic activity is reduced in the prefrontal cortex and increased in the nucleus accumbens of rats predisposed to develop amphetamine self-administration. Brain Res 567:169-174.

Piazza PV, Rouge-Pont F, Deroche V, Maccari S, Simon H, Le Moal M 
(1996) Glucocorticoids have state-dependent stimulant effects on the mesencephalic dopaminergic transmission. Proc Natl Acad Sci USA 93:8716-8720.

Pruessner JC, Hellhammer DH, Kirschbaum C (1999a) Low self-esteem, induced failure and the adrenocortical stress response. Pers Individ Diff 27:477-489.

Pruessner JC, Hellhammer DH, Kirschbaum C (1999b) Burnout, perceived stress, and cortisol responses to awakening. Psychosom Med 61:197-204.

Pruessner JC, Kirschbaum C, Meinlschmidt G, Hellhammer DH (2003) Two formulas for the computation of the area under the curve represent measures of total hormone concentration versus time-dependent change. Psychoneuroendocrinology 28:916-931.

Redgrave P, Prescott TJ, Gurney K (1999) Is the short-latency dopamine response too short to signal reward error? Trends Neurosci 22:146-151.

Rouge-Pont F, Piazza PV, Kharouby M, Le Moal M, Simon H (1993) Higher and longer stress-induced increase in dopamine concentrations in the nucleus accumbens of animals predisposed to amphetamine selfadministration. A microdialysis study. Brain Res 602:169-174.

Rouge-Pont F, Deroche V, Le Moal M, Piazza PV (1998) Individual differences in stress-induced dopamine release in the nucleus accumbens are influenced by corticosterone. Eur J Neurosci 10:3903-3907.

Salamone JD, Cousins MS, Snyder BJ (1997) Behavioral functions of nucleus accumbens dopamine: empirical and conceptual problems with the anhedonia hypothesis. Neurosci Biobehav Rev 21:341-359.

Schultz W (1998) Predictive reward signal of dopamine neurons. J Neurophysiol 80:1-27.
Smith GS, Dewey SL, Brodie JD, Logan J, Vitkun SA, Simkowitz P, Schloesser R, Alexoff DA, Hurley A, Cooper T, Volkow ND (1997) Serotonergic modulation of dopamine measured with $[11 \mathrm{C}]$ raclopride and PET in normal human subjects. Am J Psychiatry 154:490-496.

Spielberger CD, Gorusch RL, Lushene RE, Vagg PR, Jacobs GA (1977) State and trait anxiety inventory for adults. Redwood City, CA: Mind Garden.

Suri (2002) TD models of reward predictive responses in dopamine neurons. Neural Netw 15:523-533.

Talairach J, Tournoux P (1988) Co-planar stereotactic atlas of the human brain; 3-dimensional proportional system: an approach to cerebral imaging. New York: Thieme.

Volkow ND, Wang GJ, Fowler JS, Logan J, Gatley SJ, Hitzemann R, Chen AD, Dewey SL, Pappas N (1997) Decreased striatal dopaminergic responsiveness in detoxified cocaine-dependent subjects. Nature 386:830-833.

Wang GJ, Volkow ND, Fowler JS, Logan J, Pappas NR, Wong CT, Hitzemann RJ, Netusil N (1999) Reproducibility of repeated measures of endogenous dopamine competition with [11C]raclopride in the human brain in response to methylphenidate. J Nucl Med 40:1285-1291.

Wise RA, Rompre PP (1989) Brain dopamine and reward. Annu Rev Psychol 40:191-225.

Wishart D (1999) Clustan Graphics2: interactive graphics for cluster analysis. In: Classification in the information age (Locarek-Junge H, ed), pp 268-275. Berlin: Springer.

Worsley KJ, Marrett S, Neelin P, Vandal AC, Friston KJ, Evans AC (1996) A unified statistical approach for determining significant signals in images of cerebral activation. Hum Brain Mapp 4:58-73. 